\title{
Stage T1 bladder cancer: historic background and latest tracks for its demystification
}

\author{
Wolfgang Otto \\ Department of Urology, University of Regensburg, Regensburg, Germany \\ Correspondence to: Priv.-Doz. Dr. med. Wolfgang Otto, MD. Research and Study Coordinator, Department of Urology, University of Regensburg, \\ Franz-Josef-Strauß-Allee 11, Regensburg 93053, Germany. Email: wolfgang.otto@ukr.de. \\ Provenance: This is a Guest Editorial commissioned by Section Editor Xiao Li (Department of Urology, Jiangsu Cancer Hospital \& Jiangsu Institute \\ of Cancer Research \& Nanjing Medical University Affiliated Cancer Hospital, Nanjing, China). \\ Comment on: D'Andrea D, Abufaraj M, Susani M, et al. Accurate prediction of progression to muscle-invasive disease in patients with pT1G3 bladder \\ cancer: A clinical decision-making tool. Urol Oncol 2018;36:239.e1-239.e7.
}

Submitted Jun 01, 2018. Accepted for publication Jun 20, 2018.

doi: $10.21037 /$ tau.2018.06.13

View this article at: http://dx.doi.org/10.21037/tau.2018.06.13

Showing an increase between 1990 and 2010 from 114,000 to 170,000 deaths per year worldwide, today bladder cancer remains to be not only an essential but particularly challenging entity of uro-oncological treatment (1).

\section{Bladder cancer from the cradle of medicine to modern urology}

Tumors of the bladder, known for their malignancy in almost all cases might have been the very first visceral or abdominal neoplasm that became obvious for ancient medical healers (2). First, lithotomists should have found some tumors when performing bladder lithotomy procedures, although reports are absent. In the 1630 s, French lithotomist Joseph Covillard (†1660) for the first time reported of intended removal of a bladder tumor (2). Secure tumor resection was only possible after the invention of urethrocystoscopic guided electric resection tools by German "nestor of modern urology" Maximilian Nitze [1848-1906] and his co-workers and successors from the year of 1877 on (3). While grading of bladder cancer was even researched 100 years earlier by French surgeon Francois Chopart [1743-1795] who described low- and high-grade bladder carcinoma for the first time, description of the correlation between infiltration depths into the bladder wall and prognosis of bladder cancer was only performed in 1946 under participation of the US American urologist (not pathologist as frequently stated) Hugh J. Jewett [1904-1990] $(4,5)$. This first staging classification was revised by Victor F. Marshall [1913-2001], another epoch making urologist, so that in 1952 the so called Jewett-Strong-Marshall Staging was introduced (6). From 1967 on, Jewett and colleagues worked under the rules of American Joint Committee System (AJCC) to establish the TNM classification which is published by the Union Internationale Contre le cancer (UICC) scriptural statute for clinician and scientific work on bladder cancer into our days (7).

\section{Where were the pathologists?}

It was also Marshall who developed another important tool for bladder cancer diagnosis in 1945: urine cytology. Remains the question, if there were any pathologist in these days dealing with bladder carcinoma? Well, for one thing it is to say, that famous Greek-American pathologist George Papanicolaou [1883-1962] worked together with Marshall in the invention of urine cytology (8). In terms of tissue pathology Albert C. Broders [1885-1964] in 1920 set a milestone with defining grading as a main concept of prognosticating malignancy that depended with pathological eminences of the 19th century, e.g., Rudolf Virchow [1821-1902] of Berlin, until than only on penetration of tumor tissue in deeper layers of organs, in case of bladder cancer the detrusor muscle (9). In 1922, Broders transferred grading on bladder cancer and showed the prognostic importance of this concept (10). Another pathological milestone of Broders was transferred to bladder 
cancer not until 30 years later by Meyer M. Melicow [18941983], recognized Russian-American painter and first given professor of uropathology, who described carcinoma in situ of the bladder first (11). Another concept of bladder cancer stratification, at first sight somewhat primitive, but with great impact of even macroscopic prognostication is tumor growth: separation between papillary and more aggressive solid tumors, described by Viennese Bernhard Aschner [1883-1960] (7).

\section{Non muscle-invasive bladder cancer: of slowpokes, monsters and chameleons}

So we have all ingrediences that define tumors of the bladder basically until today since the 1950s: growth pattern (papillary, solid), staging, grading and definition of carcinoma in situ. These factors enable clinicians to distinguish between harmless but affectionate (high recurrence rate) papillary "superficial" bladder cancer and highly aggressive muscle-invasive stages, that even after establishing (neoadjuvant) chemotherapeutical treatment and distinct surgical procedures show of fateful outcome. In 1977, the already mentioned Victor Marshall published data on outcomes of different bladder cancer stages (of course graduated after his own, although in the meantime by TNM classification superseded, scheme) and concluded that there was hardly progress for stage B2 to D disease (12). These stages correspond to UICC stages T2b to T4 bladder cancer. But let's come back to main topic of this Editorial, stage A (after Jewett-Strong-Marshall) bladder cancer, nowadays better known as stage T1 bladder cancer (UICC). It became obvious early that summarizing non muscleinvasive tumors as "superficial" is misleading because of very different outcomes between stage Ta, stage Tis (incidentally summarized as stage 0 by Jewett and Marshall) and stage T1 bladder carcinomas. And especially earlyinvasive cancer, coming from invading the suburethral layer but not detrusor muscle, became known for unpredictable outcomes.

\section{"Shahin's rule" and its fruitful consequences for stage $\mathrm{T} 1$ bladder cancer research}

In 2003, an exciting article appeared that made a very plastic contribution on the oncologic weight of early-invasive stage T1G3 bladder cancer, leading to high notability of its first author, Suisse urologist Osama Shahin (born 1965) (13). "Shahin's rule", his finding that one third of stage T1G3 patients show never recurrence, one third will need deferred cystectomy and finally nearly one third ultimately dies of the disease, meant an important launch for new investigations in this field. Since then publications on the topic indexed in PubMed were more than doubled compared to the three decades before, even eight times higher than in the 1970s alone. In order to better define prognostic and treatment rules for the large but prognostically unforeseeable group of non-muscle-invasive bladder carcinoma (NMIBC) the European Organisation for Research and Treatment of Cancer (EORTC) established risk factors leading to a definition of risk groups of NMIBC. But even when these risk groups were published in 2006 it was clear that prognostication of stage T1 bladder cancer could not be defined consciously by the mentioned factors: number and size of tumors, tumor stage and grade, associated carcinoma in situ and prior recurrence rate (14).

\section{One problem of EORTC risk groups: definition and assessment of tumor grading}

A number of increasingly multidisciplinary study groups of urologists and pathologists since then work on how to better define prognosis of stage T1 bladder cancer. But there are yet problems with existing "standard" EORTC risk factors, especially grading. Observations of pathologists that well differentiated early-invasive bladder carcinoma would not play a role in this subentity, came up even before defining mentioned risk tables. This was proven 2005 by Pawel Mikulowski (born 1930) in a reassessment study on 98 formerly staged T1G1 tumors that were either falsely upstaged (from stage Ta) or not well-differentiated (15). Even before a new version of bladder cancer grading of the world health organization (WHO) and International Society of Urological Pathology (ISUP) was worked up to establish a new bilateral grading system (low- vs. high-grade) that should replace the WHO grading classification of 1973 with its three-tiered system. Main cause of this project was to avoid a typical "urge to the middle", often leading to assess G2 tumors (16). Nevertheless, experienced uropathologists soon registrated that WHO grading 2004 would not be suitable for early-invasive bladder cancer. This suggestion was proved for the first time by the author and colleagues in an unicentric German survey of 310 patients with stage T1 bladder cancer in 2010: it became obvious that WHO 1973 grading classification (with again only G2 and G3 tumors assessed) was more suitable for prognostication than the differentiation between low- and high-grade tumors after 
WHO 2004 grading classification (17).

\section{Finding new prognosticators for early-invasive bladder cancer}

A limitation of almost all stage T1 bladder cancer studies is a relatively low number of patients. In their current work main author David D'Andrea and his chief, well known and recognised Shahrokh F. Shariat, urologists of Vienna Medical University, and their international coworkers present- to my knowledge for the first timea multicentric study collective of nearly 1,300 patients of stage T1G3 bladder carcinoma (18). Lately especially European urologists and pathologists are networking more and more effective in the field, leading to large collectives with meaningful results (19) or brand new study approaches, e.g., value of hormone receptors and other biomarker analyses, e.g., Bladder Cancer Research Initiative for Drug Targets Germany (BRIDGE) (20). But biomarker research (as soon reliable and valuable markers are found) as well as new local or systemic treatment approaches that might have extraordinary consequences for prognosis of bladder cancer is another story...

Back to D'Andrea's and coworkers' first nomogram for stage T1G3 bladder cancer, taking traditional NMIBC risk factors tumor size, number of tumors and associated carcinoma in situ, variant histology and lymphovascular invasion were involved in this nomogram. Both factors were the only independent prognostic factors in multivariate analysis. Perhaps exchange of associated carcinoma in situ and multifocality, that failed even in univariate analysis by far statistical significance, by metric stage $\mathrm{T} 1$ substaging and growth pattern of the invasion front might even improve the D'Andrea nomogram $(18,21)$. Let's try!

\section{Acknowledgements}

None.

\section{Footnote}

Conflicts of Interest: The author has no conflicts of interest to declare.

\section{References}

1. Lozano R, Naghavi M, Foreman K, et al. Global and regional mortality from 235 causes of death for 20 age groups in 1990 and 2010: a systematic analysis for the Global Burden of Disease Study 2010. Lancet 2012;380:2095-128.

2. Al Sudani M, Mohammed A. Historical development of diagnosis and treatment of bladder cancer. Eur Urol Suppl 2013;12:e39.

3. Jahr R. 75 Years of cystoscopy. Munch Med Wochenschr 1954;96:447-8.

4. Zorgniotti AW. Bladder cancer in the pre-cystoscopic era. Prog Clin Biol Res 1984;162A:1-9.

5. Jewett HJ, Strong GH. Infiltrating carcinoma of the bladder; relation of depth of penetration of the bladder wall to incidence of local extension and metastases. J Urol 1946;5 5:366-72.

6. Boorjian S, Vaughan ED Jr, Pitts WR Jr, et al. Victor Fray Marshall: twentieth century renaissance urologist. J Urol 2006;175:43-5.

7. Kulkarni JN, Bakhsi GK. Staging of transitional cell carcinoma: Has anything changed? Indian J Urol 2008;24:68-71.

8. Papanicolaou GN, Marshall VF. Urine sediment smears as a diagnostic procedure in cancers of the urinary tract. Science 1945;101:519-20.

9. Wright JR Jr. Albert C. Broders' paradigm shifts involving the prognostication and definition of cancer. Arch Pathol Lab Med 2012;136:1437-46.

10. Cummings KB. Clinical versus pathologic staging and the classification of bladder cancer. Urology 1984;23:55-62.

11. Melicow MM, Hollowell JW. Intra-urothelial cancer: carcinoma in situ, Bowen's disease of the urinary system: discussion of thirty cases. J Urol 1952;68:763-72.

12. Marshall VF, McCarron JP Jr. The curability of vesical cancer: greater now or then? Cancer Res 1977;37:2753-5.

13. Shahin O, Thalmann GN, Rentsch C, et al. A retrospective analysis of 153 patients treated with or without intravesical bacillus Calmette-Guerin for primary stage T1 grade 3 bladder cancer: recurrence, progression and survival. J Urol 2003;169:96-100; discussion 100.

14. Sylvester RJ, van der Meijden AP, Oosterlinck W, et al. Predicting recurrence and progression in individual patients with stage Ta T1 bladder cancer using EORTC risk tables: a combined analysis of 2596 patients from seven EORTC trials. Eur Urol 2006;49:466-5; discussion 475-7.

15. Mikulowski P, Hellsten S. T1 G1 urinary bladder carcinoma: fact or fiction? Scand J Urol Nephrol 2005;39:135-7.

16. Miyamoto H, Miller JS, Fajardo DA, et al. Non-invasive 
papillary urothelial neoplasms: the 2004 WHO/ISUP classification system. Pathol Int 2010;60:1-8.

17. Otto $W$, Denzinger S, Fritsche HM, et al. The WHO classification of 1973 is more suitable than the WHO classification of 2004 for predicting survival in pT1 urothelial bladder cancer. BJU Int 2011;107:404-8.

18. D'Andrea D, Abufaraj M, Susani M, et al. Accurate prediction of progression to muscle-invasive disease in patients with pT1G3 bladder cancer: A clinical decisionmaking tool. Urol Oncol 2018;36:239.e1-239.e7.

19. van de Putte EEF, Bosschieter J, van der Kwast TH, et al. The World Health Organization 1973 classification

Cite this article as: Otto W. Stage T1 bladder cancer: historic background and latest tracks for its demystification. Transl Androl Urol 2018;7(4):760-763. doi: 10.21037/tau.2018.06.13 system for grade is an important prognosticator in T1 non-muscle-invasive bladder cancer. BJU Int 2018. [Epub ahead of print].

20. Breyer J, Otto W, Wirtz RM, et al. ERBB2 Expression as Potential Risk-Stratification for Early Cystectomy in Patients with pT1 Bladder Cancer and Concomitant Carcinoma in situ. Urol Int 2017;98:282-9.

21. Otto $W$, van Rhijn BW, Breyer J, et al. Infiltrative lamina propria invasion pattern as an independent predictor for cancer-specific and overall survival of instillation treatment-naïve stage T1 high-grade urothelial bladder cancer. Int J Urol 2018;25:442-9. 